\title{
Changing Trends of Angiographic Profiles in Women with Coronary Artery Disease over a Decade
}

\author{
Sunitha Aramalla ${ }^{1}$ Priyanka Chakkera \\ ${ }^{1}$ Department of Cardiology, NIMS, Punjagutta, Hyderabad, \\ Telangana, India \\ 2Department of General Medicine, NIMS, Punjagutta, Hyderabad, \\ Telangana, India \\ Indian J Cardiovasc Dis Women-WINCARS 2018;3:217-220
}

\begin{abstract}
Address for correspondence Sunitha Aramalla, DM, Department of Cardiology, NIMS, Punjagutta, Hyderabad 500082, Telangana, India (e-mail: Sunitha.aramalla@gmail.com).
\end{abstract}

\begin{abstract}
Background Cardiovascular diseases, especially coronary artery disease (CAD), have assumed epidemic proportions worldwide. CAD is the leading cause of disability and death in women. In woman during postmenopausal years, traditional risk factors tend to become very present and increase the risk for CAD. Patterns in epidemiology of CAD are doubtlessly changing continually in many ways, only some of which are recognized at any given point of time.

Aim To identify the changing trends of CAD in female patients who were admitted for coronary angiogram (CAG) over a period of 10 years.

Materials and Methods We retrospectively collected the data of female patients from our unit CAG registry. We noted the demographic data (age, ethnicity, socioeconomic status), clinical data (diabetic status, hypertension status, symptoms and their duration, past history), laboratory data (complete blood picture, cardiac enzymes, renal function tests, liver function tests, serum electrolytes), and CAG findings (normal coronaries [NC]/single-vessel disease [SCD]/double-vessel disease [DVD]/triple-vessel disease [TVD]) of the female patients in 2007 and a decade later that was 2017.

Results Data of 64 women in 2007 and of 184 in 2017 were analyzed. CAG women in 2017 were older than those in 2007 ( $53.1 \pm 11.7$ vs. $57.1 \pm 12.3$ years; $p=0.024$ ). There was no significant difference found in the parameters such as hypertension ( $p=0.797)$, diabetes mellitus (DM) (37.5\% vs. 41.3\%; $p=0.59)$, left ventricular (LV) dysfunction, type of presentation (acute coronary syndrome [ACS] or chronic stable angina [CSA]) and presence of CAD (53.9\% vs. 51.1\%; $p=0.69)$. In the 2017 female group, there was increase in detection of the electrographic (ECG) abnormalities (98.4\% vs. $62.5 \% ; p=0.000$ ). Radial route was used more frequently for CAG ( $98.4 \%$ vs. $40.6 \%$; $p=0.000$ ). Subgroup analysis of CAD (proven angiographically) showed a statistically

Keywords

- coronary artery disease

- females

- coronary angiogram

- changing trends significant difference of occurrence of SVD that was more frequent in 2007 female group (32.8\% vs. 20.1\%; $p=0.05$ ), whereas TVD (was more frequent in 2017 female group ( $14.1 \%$ vs. $4.6 \%$; $p=0.01)$.

Conclusion This study shows that even though there was no change in the incidence of occurrence of normal coronaries on angiogram over time; however, there was a significant increase in severity of the CAD (TVD) in 2017 female group $(p=0.01)$.
\end{abstract}

DOI https://doi.org/

$10.1055 / \mathrm{s}-0039-1679103$
C. 2018 Women in Cardiology and Related Sciences
License terms

(요 (1) $\odot$ 


\section{Introduction}

In the second half of the 20th century, greater attention is paid to the underlying risk factors and strategies for cardiovascular disease prevention. ${ }^{1}$ For that, we should have better idea about changing trends of coronary artery disease (CAD) in our Asian continent. As there are very limited studies on this topic, we targeted to know the changing trends of CAD in women over a period of 10 years.

\section{Materials and Methods}

We retrospectively collected the data of female patients from our unit CAG (coronary angiogram) registry. We noted the demographic data (age, ethnicity, socioeconomic status), clinical data (diabetic status hypertensive status, duration and severity of symptoms), laboratory data (electrocardiogram [ECG], echocardiography [ECHO], complete hemogram, renal function tests, liver function tests, serum electrolytes), and CAG findings (normal coronaries [NC]/single-vessel disease [SVD]/double-vessel disease [DVD]/triple-vessel disease [TVD]) of the female patients in 2007 and a decade later that was 2017. The results were compared between the two groups across various parameters.

\section{Results}

Total number of CAG data analyzed in 2007 and 2017 were 64 and 184 cases, respectively. Demographic data, clinical data, investigative data, and angiogram-wise CAD of the both groups are mentioned in - Table 1.

Coronary angiogram women in 2017 were older than those in 2007, and the observation was statistically significant ( $53.1 \pm 11.7$ vs. $57.1 \pm 12.3 ; p=0.024$ ). There was no significant difference found in the parameters such as hypertension
(HTN) (65.6 vs. 67.4\%; $p=0.795)$, diabetes mellitus (DM) (37.5 vs. $41.3 \% ; p=0.59$ ), and presence of CAD (53.9 vs. $51.1 \% ; p=0.778)$. In 2017 female group, there was increase in detection of the electrocardiographic (ECG) abnormalities (98.4 vs. 62.5\%; $p=0.000$ ), and the route of access to CAG was more through radial than femoral ( 98.4 vs. $40.6 \% ; p=0.000$ ). There was no significant difference found between both the groups regarding the left ventricular (LV) dysfunction (14.7 vs. $7.8 \% ; p=0.12$ ) and the incidence of acute coronary syndrome (ACS) (26.6 vs. 28.1\%; $p=0.82$ ) (-Fig. 1).

Normal coronaries or insignificant coronary disease was present in 30 (53.9\%) in 2007 versus 90 (59.1\%) in 2017, which was not statistically significant $(p=0.778)$. In subgroup analysis of CAD (proven angiographically), the relative differences of severity of involvement of coronaries were evaluated, which showed a statistically significant difference of occurrence of SVD that was more frequent in 2007 female group (32.8 vs. 20.1\%; $p=0.38$ ), whereas TVD was more in 2017 female group (14.1 vs. 4.6\%; $p=0.04$ ). There was no difference found in the DVD in between the two groups (16.8 vs. 15.6\%; $p=0.82$ ) (-Fig. 2, - Table 2).

\section{Discussion}

Coronary artery disease is the major cause of morbidity and mortality across the world, and it has major impact on both developing and developed nations. In India studies regarding prevalence of CAD date back to 1960. In the year 2010, the World Health Organization (WHO) reported 5.87 million deaths globally due to noncommunicable diseases among which 0.9 million deaths were in women and 1.2 million deaths were in men. Age-adjusted CAD mortality rates were 153 in 100,000 in women in Bangladesh, 294 in 100,000 in women in Pakistan, and 265 in 100,000 in women in India. These rates are two to three times greater than those in the United States where rates

Table 1 Comparison of parameters between 2007 and 2017

\begin{tabular}{|c|c|c|c|}
\hline Parameter & $2007(n=64)$ & $2017(n=184)$ & $p$ Value \\
\hline Age (y) & $53.1 \pm 11.7$ & $57.1 \pm 12.3$ & 0.024 \\
\hline HTN & $42(65.6 \%)$ & $124(67.4 \%)$ & 0.795 \\
\hline DM & $24(37.5 \%)$ & $76(41.3 \%)$ & 0.590 \\
\hline ECG abnormality & 40 (63.5\%) & $181(98.4 \%)$ & 0.000 \\
\hline LV dysfunction & $5(4.7 \%)$ & $27(7.8 \%)$ & 0.158 \\
\hline Type of presentation & $\begin{array}{l}\text { ACS } \\
18(28.1 \%) \\
\text { CSA } 46(71.9 \%)\end{array}$ & $\begin{array}{l}\text { ACS } \\
49(29.8 \%) \\
\text { CSA } 115(\%)\end{array}$ & $\begin{array}{l}0.82 \\
0.175\end{array}$ \\
\hline Radial route & $26(41.3 \%)$ & 181 (98.4\%) & 0.000 \\
\hline \multicolumn{4}{|l|}{ CAD } \\
\hline $\mathrm{NC}$ & 30 (53.9\%) & 90 (51.1\%) & 0.778 \\
\hline SVD & $21(32.8 \%)$ & 37 (20.1\%) & 0.386 \\
\hline DVD & $10(15.6 \%)$ & $31(16.8 \%)$ & 0.051 \\
\hline TVD & $3(4.6 \%)$ & $26(14.1 \%)$ & 0.042 \\
\hline
\end{tabular}

Abbreviations: ACS, acute coronary syndrome; CAD, coronary artery disease; CSA, chronic stable angina; DM, diabetes mellitus; DVD, double-vessel disease; ECG, electrocardiogram; HTN, hypertension; LV, left ventricular; NC, normal coronaries; SVD, single-vessel disease; TVD, triple-vessel disease. 


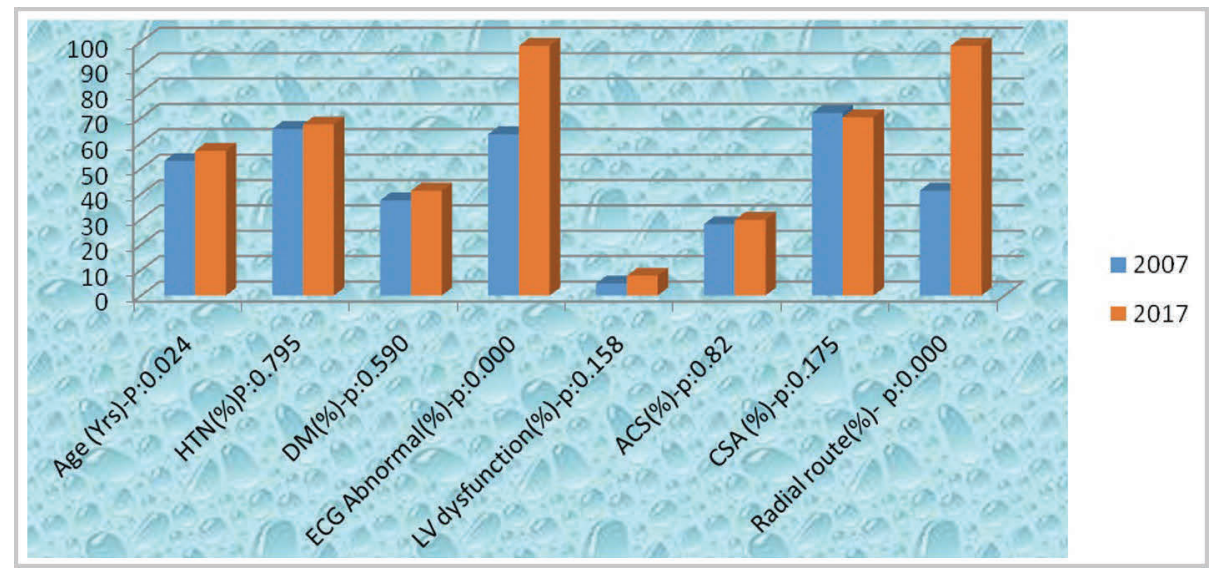

Fig. 1 Comparison of various parameters over a decade. ACS, acute coronary syndrome; CSA, chronic stable angina; DM, diabetes mellitus; ECG, electrocardiogram; HTN, hypertension; LV, left ventricular.

Table 2 Comparison of age-matched severity of CAD in 2007 and 2017

\begin{tabular}{|c|c|c|c|c|c|c|c|c|c|c|c|c|c|}
\hline \multirow{2}{*}{$\begin{array}{l}\text { Age } \\
\text { (y) }\end{array}$} & & \multicolumn{3}{|c|}{ Normal coronaries } & \multicolumn{3}{|c|}{ Single-vessel disease } & \multicolumn{3}{|c|}{ Double-vessel disease } & \multicolumn{3}{|c|}{ Triple-vessel disease } \\
\hline & $\begin{array}{l}2007, \\
2017\end{array}$ & 2007 & 2017 & $\begin{array}{l}p \\
\text { Value }\end{array}$ & 2007 & 2017 & $p$ Value & 2007 & 2017 & $\begin{array}{l}p \\
\text { Value }\end{array}$ & 2007 & 2017 & $\begin{array}{l}p \\
\text { Value }\end{array}$ \\
\hline$<50$ & $\begin{array}{l}2007- \\
23 \\
2017- \\
54\end{array}$ & $\begin{array}{l}7 \\
(30.4 \%)\end{array}$ & $\begin{array}{l}34 \\
(62.9 \%)\end{array}$ & 0.005 & $\begin{array}{l}10 \\
(43.5 \%)\end{array}$ & $\begin{array}{l}8 \\
(14.8 \%)\end{array}$ & 0.012 & $\begin{array}{l}4 \\
(17.3 \%)\end{array}$ & $\begin{array}{l}7 \\
(12.9 \%)\end{array}$ & 0.63 & $\begin{array}{l}2 \\
(86.9 \%)\end{array}$ & $\begin{array}{l}5 \\
(9.3 \%)\end{array}$ & 0.94 \\
\hline$>50$ & $\begin{array}{l}2007- \\
41 \\
2017- \\
130\end{array}$ & $\begin{array}{l}23 \\
(56.1 \%)\end{array}$ & $\begin{array}{l}56 \\
(43.1 \%)\end{array}$ & 0.14 & $\begin{array}{l}11 \\
(26.8 \%)\end{array}$ & $\begin{array}{l}29 \\
(22.3 \%)\end{array}$ & 0.56 & $\begin{array}{l}6 \\
(14.6 \%)\end{array}$ & $\begin{array}{l}24 \\
(18.5 \%)\end{array}$ & 0.56 & $1(2.4 \%)$ & $\begin{array}{l}21 \\
(16.4 \%)\end{array}$ & 0.001 \\
\hline
\end{tabular}

Abbreviation: CAD, coronary artery disease.

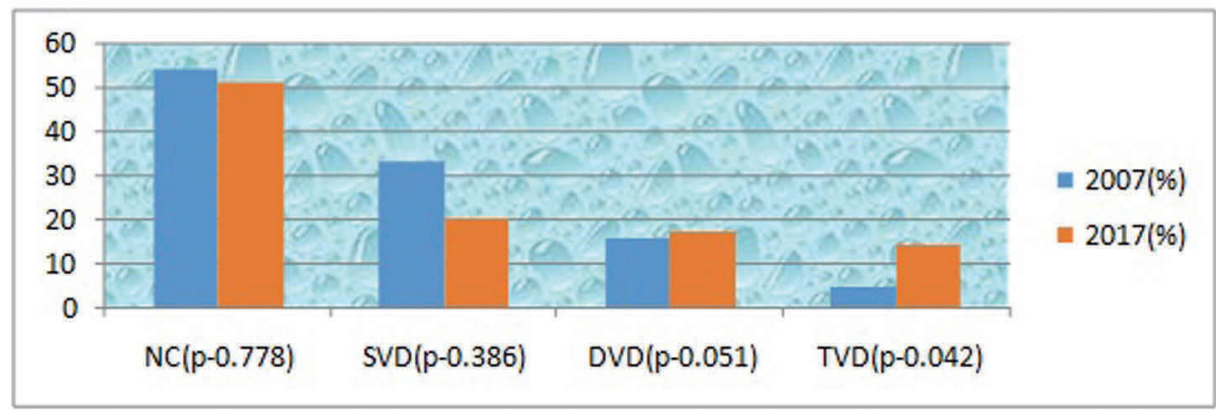

Fig. 2 Comparison of severity of CAD over a decade. DVD, double-vessel disease; NC, normal coronaries; SVD, single-vessel disease; TVD, triplevessel disease.

are 108 in 100,000 in women. ${ }^{2}$ Prevalence of CAD was 6.5 times higher in men compared with womem. ${ }^{3}$ The first Indian study by Dewan et al involving Minnesota codes was done in 1974, which reported CAD prevalence of $2.28 \%$ in men and $1.73 \%$ in women in rural Maharashtra. ${ }^{4}$ In 1991-1994, ICMR (Indian Council of Medical Research) task force study was conducted in which CAD prevalence rates were $11 \%$ and 10\% in urban Delhi among men and women, respectively. In 1992-1995 and 2001, studies conducted by Gupta et al showed prevalence rates of CAD $(5.96 \%$ and $6.18 \%$ ) and (10.5\% and $10.1 \%$ ) among men and women, respectively. ${ }^{5,6}$ In APRHI (Andhra Pradesh Rural Health Initiative)
180,162 rural participants in Andhra Pradesh were prospectively studied for incidence of CAD mortality over 2 years, and mortality rate was 225 in 100,000 in women, and it emerged as the most important cause of death. ${ }^{7}$ PROLIFE (Kerala-based Population Registry of Lifestyle Diseases) evaluated causes of deaths in 161,942 population-based men and women over a 7 -year period and reported death rates from CAD in women 231/100,000. ${ }^{8}$ Cross-sectional survey was performed between 1991-1994 and 2010-2012 in a rural block in Vellore district and in Vellore town in Tamil Nadu by Oommen et al. ${ }^{9}$ It observed a threefold rise in urban areas with a modest rise among men 
and a twofold rise in the prevalence of CAD among women in rural areas. Our study showed that even though there was no change in the incidence of occurrence of normal coronaries on angiogram over time, there was a significant rise in severity of the CAD (TVD) in the 2017 female group ( $p=0.01$ ).

The WHO Working Group has developed a major international collaborative study (Monica Study) with the objective of measuring trends of CAD over 10 years, which showed declining trends. ${ }^{10}$ Atherosclerosis Risk in Communities (ARIC) study, ${ }^{11}$ was an ongoing population-based cohort of 15,792 men and women aged 45 to 64 years, and it showed declining trends of CAD.

The key contributors to the rise in CAD across countries at all stages of development included physical inactivity, unhealthy dietary changes, dyslipidemia, and tobacco use. In this study among the patients admitted for CAG, we found that incidence of HTN (65.6 vs. 67.4\%) and DM (37.5 vs. $41.3 \%$ ) did not change from 2007 to 2017.

Much has been discussed in previous studies about the CAD preventive life of women till menopause. It is assumed that in women during the fertile period exposure to endogenous estrogens of life, there are delays in the manifestation of atherosclerotic disease. ${ }^{12}$ A prospective study of almost 25,000 patients showed that the relative risk of myocardial infarction in female smokers exceeded that of male smokers by more than $50 \%$ before menopause. The risks associated with smoking did not depend on age. ${ }^{13}$

A study analyzed data from a breast cancer screening cohort comprising 12,134 postmenopausal women followed for an average of 17 years, which showed that women with an early menopause (< 40 years) have a 2-year lower life expectancy compared with those with a normal or late menopause. ${ }^{14}$

Framingham Heart Study showed that a harmful cardiovascular risk profile may be more cause than consequence of age at menopause. In the Women's Ischemia Syndrome Evaluation (WISE) study, ${ }^{15}$ women are followed for at least 1 year to assess clinical events and symptom status. It was shown that young women with endogenous estrogen deficiency have a more than sevenfold increase in coronary artery risk. ${ }^{16}$ After menopause, atherosclerotic plaque composition changes into more vulnerable lesions with inflammatory factors involved. ${ }^{17}$

In this study, 2017 CAG women were older than 2007 CAG women, so the authors have not taken menopausal age into consideration.

The finding that ECG abnormalities were also increased in 2017 female group without change in LV function or type of presentation (ACS vs, CSA) is important in this study. Also, another important finding includes increased incidence of TVD in 2017 female group when compared with 2007 female group. This increased incidence of TVD could be due to the higher age group of population in 2017 or older women agreeing (and or referred) to undergo invasive evaluation.

\section{Conclusion}

This study shows that 2017 female CAG patients are older than 2007 group. Even though there was no change in the incidence of occurrence of NC on angiogram over time, there was a significant increase in severity of the CAD (TVD) in 2017 female group ( $p=0.04$ ). ECG abnormalities were also increased in 2017 female group without change in LV function or type of presentation (ACS).

\section{Conflict of Interest}

None.

\section{References}

1 Reid CM, Owen AJ, Freedman B. Coronary artery disease epidemics: not all the same. Medicographia 2014;36:11-18

2 World Health Organization. Global Status Report on Non-Communicable Diseases 2014. Geneva, Switzerland: World Health Organization; 2014

3 Sriharibabu M. Changing trends in the prevalence of coronary heart disease. Indian Heart J 2016;68(4):445-446

4 Dewan BD, Malhotra KC, Gupta SP. Epidemiological study of coronary heart disease in rural community in Haryana. Indian Heart J 1974;26(2):68-78

5 Gupta R, Gupta VP. Meta-analysis of coronary heart disease prevalence in India. Indian Heart J 1996;48(3):241-245

6 Gupta R, Guptha S, Sharma KK, Gupta A, Deedwania P. Regional variations in cardiovascular risk factors in India: India heart watch. World J Cardiol 2012;4(4):112-120

7 Joshi R, Cardona M, Iyengar S, et al. Chronic diseases now a leading cause of death in rural India-mortality data from the Andhra Pradesh Rural Health Initiative. Int J Epidemiol 2006;35(6):1522-1529

8 Soman CR, Kutty VR, Safraj S, Vijayakumar K, Rajamohanan K, Ajayan K; PROLIFE Study Group. All-cause mortality and cardiovascular mortality in Kerala state of India: results from a 5-year follow-up of 161,942 rural community dwelling adults. Asia Pac J Public Health 2011;23(6):896-903

9 Oommen AM, Abraham VJ, George K, Jose VJ. Rising trend of cardiovascular risk factors between 1991-1994 and 20102012: a repeat cross sectional survey in urban and rural Vellore. Indian Heart J 2016;68(3):263-269

10 Principal Investigators, The World Health Organization MONICA Project. (monitoring trends and determinants in cardiovascular disease): a major international collaboration. WHO MONICA Project. J Clin Epidemiol 1988;41(2):105-114

11 The ARIC investigators. The Atherosclerosis Risk in Communities (ARIC) study: design and objectives. The ARIC investigators. Am J Epidemiol 1989;129(4):687-702

12 Maas AHEM, Appelman YEA. Gender differences in coronary heart disease. Neth Heart J 2010;18(12):598-602

13 Prescott E, Hippe M, Schnohr P, Hein HO, Vestbo J. Smoking and risk of myocardial infarction in women and men: longitudinal population study. BMJ 1998;316(7137):1043-1047

14 Ossewaarde ME, Bots ML, Verbeek AL, et al. Age at menopause, cause-specific mortality and total life expectancy. Epidemiology 2005;16(4):556-562

15 Merz CN, Kelsey SF, Pepine CJ, et al. The Women's Ischemia Syndrome Evaluation (WISE) study: protocol design, methodology and feasibility report. J Am Coll Cardiol 1999;33(6):1453-1461

16 Bairey Merz CN, Johnson BD, Sharaf BL, et al; WISE Study Group. Hypoestrogenemia of hypothalamic origin and coronary artery disease in premenopausal women: a report from the NHLBI-sponsored WISE study. J Am Coll Cardiol 2003;41(3):413-419

17 Sutton-Tyrrell K, Lassila HC, Meilahn E, Bunker C, Matthews KA, Kuller LH. Carotid atherosclerosis in premenopausal and postmenopausal women and its association with risk factors measured after menopause. Stroke 1998;29(6):1116-1121 